\title{
Differential expression of anterior gradient gene AGR2 in prostate cancer
}

\author{
Erin L Maresh', Vei Mah', Mohammad Alavi ${ }^{1}$, Steve Horvath ${ }^{2,3}$, Lora Bagryanova, Emily S Liebeskind ${ }^{4,5}$, \\ Laura A Knutzen ${ }^{6}$, Yong Zhou ${ }^{6}$, David Chia ${ }^{1,7}$, Alvin Y Liu ${ }^{4,5}$, Lee Goodglick ${ }^{1,7^{*}}$
}

\begin{abstract}
Background: The protein AGR2 is a putative member of the protein disulfide isomerase family and was first identified as a homolog of the Xenopus laevis gene XAG-2. AGR2 has been implicated in a number of human cancers. In particular, AGR2 has previously been found to be one of several genes that encode secreted proteins showing increased expression in prostate cancer cells compared to normal prostatic epithelium.

Methods: Gene expression levels of AGR2 were examined in prostate cancer cells by microarray analysis. We further examined the relationship of AGR2 protein expression to histopathology and prostate cancer outcome on a population basis using tissue microarray technology.

Results: At the RNA and protein level, there was an increase in AGR2 expression in adenocarcinoma of the prostate compared to morphologically normal prostatic glandular epithelium. Using a tissue microarray, this enhanced AGR2 expression was seen as early as premalignant PIN lesions. Interestingly, within adenocarcinoma samples, there was a slight trend toward lower levels of AGR2 with increasing Gleason score. Consistent with this, relatively lower levels of AGR2 were highly predictive of disease recurrence in patients who had originally presented with high-stage primary prostate cancer $(P=0.009)$.

Conclusions: We have shown for the first time that despite an increase in AGR2 expression in prostate cancer compared to non-malignant cells, relatively lower levels of AGR2 are highly predictive of disease recurrence following radical prostatectomy.
\end{abstract}

\section{Background}

It is estimated that in 2010 , there will be over 217,000 new cases of prostate cancer and over 32,000 deaths from this disease in the United States alone, making it the most common male cancer and the second leading cause of cancer-related deaths in men [1]. Prostate cancer is generally diagnosed by serum level of prostatespecific antigen (PSA) and digital rectal exam. However, although PSA is abundantly synthesized by the prostate, it is not cancer specific, leading to many unnecessary biopsies. Improved markers for both identifying prostate cancer and predicting its outcome are needed. Our approach to discover such markers involved comparative analysis of the transcriptomes of cancer cells and

\footnotetext{
* Correspondence: Igoodglick@mednet.ucla.edu

'Department of Pathology and Laboratory Medicine, David Geffen School of Medicine, University of California, Los Angeles, 10833 Le Conte Ave., Los Angeles, CA 90095, USA

Full list of author information is available at the end of the article
}

normal cells. These transcriptomes were determined through sorting of specific cell types from appropriate tissue specimens for analysis by Affymetrix DNA microarrays [2]. Genes that were found overexpressed by 8fold or more in cancer cells were biomarker candidates, especially those that encode secreted or extracellular proteins. The coding sequences were analyzed with SignalP 2.0 [3] for signal peptides and TMHMM [4] for protein topology and the number of transmembrane helices. AGR2 (anterior gradient 2) was one among several such genes identified as overexpressed in prostate cancer cells. The array signal level for AGR2 in the cancer cells was $\sim 50$-fold higher than that in luminal cells, the normal counterpart [5].

AGR2 is the human homolog of the protein XAG-2 in Xenopus laevis and was first identified as differentially expressed in estrogen receptor positive breast cancer cell lines [6]. Biochemically, AGR2 is classified as a member of the protein disulfide isomerase (PDI) family 
based on amino acid sequence homology [7]. PDI enzymes in the endoplasmic reticulum act as molecular chaperones for protein folding. As such, AGR2 is thought to act as a chaperone to clear misfolded proteins out of cells during periods of physiological stress [8]. Studies have found that AGR2 expression can be increased in response to physiological stress in breast cancer cells and can enhance survival of damaged lung cancer cells $[8,9]$. PDI enzymes are found in other subcellular compartments and are thought to participate in or modulate a range of functions, from cell adhesion to DNA binding [10-12].

Several cancers, including breast [13-16], prostate [17-21], fibrolamellar [22], pancreatic [23-25], and colon [26], have been found to express increased levels of AGR2 compared to normal tissue. Furthermore, AGR2 has been shown to increase tumor cell migration in vitro and the incidence of metastatic lesions in vivo $[15,18,21,27]$. Accordingly, some studies have found AGR2 to be a marker of poor prognosis in human breast and prostate cancers $[14,19,28,29]$. One the other hand, some studies have found AGR2 to show no association with patient outcome in lung and pancreatic cancer $[23,30]$ or even improved outcome in breast cancer [13].

To further evaluate the utility of AGR2 as a cancer biomarker, we examined the expression pattern of AGR2 in prostate cancer using both gene expression analysis and a high-density tissue microarray.

\section{Methods}

\section{Gene expression analysis of AGR2 in prostate cancer}

Two publically available datasets were used to examine AGR2 gene expression in human prostate samples $[31,32]$. The first dataset was generated using Affymetrix U95B Array (GEO Accession number GDS2546) [31]. It included 66 prostate cancer tissues, 17 normal prostate tissues, and 25 metastatic prostate tumor samples obtained from 4 patients. The second data set was generated using a cDNA microarray from the Stanford Microarray Database (GEO Accession number GSE3933) [32]. The dataset included 62 primary tumor tissues, 41 matched normal prostate tissues, and 9 unmatched pelvic lymph node metastases. For all datasets we used the peer-reviewed normalization procedures described by the authors. We downloaded the normalized data from the GEO database.

\section{Prostate tissue microarray analysis}

Formalin-fixed, paraffin-embedded archival tumor specimens were obtained from 187 patients who underwent radical retropubic prostatectomy between 1984 and 1995 at the UCLA Medical Center. The construction of the prostate tissue microarray (TMA) and the utilization of the TMA were performed under appropriate UCLA IRB approval. Case material was reviewed for TMA construction by a study pathologist. At least three core tissue biopsies $0.6 \mathrm{~mm}$ in diameter were taken from morphologically representative regions of each prostate tumor and arrayed as previously described [33-35]. Matched benign (morphologically normal or benign prostatic hyperplasia/BPH) and in situ lesions of prostatic intraepithelial neoplasia (PIN) were also included. The prostate TMA was evaluated for AGR2 expression using a standard immunohistochemistry protocol as previously described [33-36]. Briefly, 4 micron sections were cut from each array block. Following deparaffinization and antigen retrieval, endogenous peroxidases were quenched and tissue was blocked with goat serum. Slides were incubated with rabbit polyclonal anti-AGR2 antibody at 1:400 (NB110-17780, Novus Biologicals, Littleton, $\mathrm{CO}$ ) overnight at $4^{\circ} \mathrm{C}$. Specific staining was detected by applying goat anti-rabbit horseradish peroxidase-conjugated secondary antibody and avidin-biotin complex followed by diaminobenzidine (Vector ABC, Burlingame, CA). If a tissue was positive for expression, only glandular epithelium stained. Moreover, the antiAGR2 staining showed a dose-dependent titration of signal. Human colonic epithelium was used as a positive control for antibody staining. For negative control, tissue was incubated with concentration-matched non-immune rabbit IgG. Negative controls demonstrated no staining.

Staining frequency and intensity of AGR2 expression on the TMA was assessed by our pathologist (M.A.) and spot-checked by a second pathologist (V.M.) as described previously $[34,36]$. The correlation coefficient between scores from the two pathologists was $r=0.95$. The percentage of glandular cells staining was scored from $0-100 \%$ and the intensity of staining was rated from 0 for below the level of detection to 3 for strong expression. An integrated measure of expression for frequency and intensity of staining was calculated using the following formula: $[3(\% x)+2(\% y)+1(\% z)] / 100$, where $\mathrm{x}, \mathrm{y}$, and $\mathrm{z}$ represented the percentage of cells staining at intensity 3,2 , and 1 , respectively. For outcomes analysis, a mean pooled value for each case was determined as described previously [34-37].

\section{Statistical analysis}

Statistical analyses were conducted as previously reported [34,36-38]. Briefly, non-parametric two-group and multi-group comparisons were carried out using Mann-Whitney and Kruskal-Wallis tests. Correlations were calculated using Spearman correlations. Patients were dichotomized at the $75^{\text {th }}$ percentile of AGR2 expression, and survival curves were visualized using the Kaplan-Meier plot with the difference between survival distributions assessed by the log-rank test. The Cox 
proportional hazards model was used to test the statistical significance of predictors in both a univariate and a multivariate setting. All statistical analyses were performed with StatView Version 5.0 (SAS Institute, Cary, $\mathrm{NC}$ ) or with the freely available software package $\mathrm{R}$ http://www.r-project.org.

\section{Results}

\section{AGR2 mRNA expression in human prostate tissue}

Several malignancies have been shown to express increased levels of AGR2 compared to non-malignant tissue. To further evaluate the utility of AGR2 as a cancer biomarker, we examined the gene expression pattern of AGR2 in human prostate cancer compared to nonmalignant prostatic glandular epithelium. To do this we analyzed AGR2 expression from two large publically available datasets from the GEO database from which normalized results were available [31,32]. Figure $1 \mathrm{~A}$ and $1 \mathrm{~B}$ show mean relative expression values for each dataset. In both populations, AGR2 transcript levels were significantly higher in primary prostate cancer tissue compared to non-malignant prostate. Interestingly, transcript levels of AGR2 in metastatic lesions were also lower than the associated primary tumor (Figure 1A and 1B).

\section{Differential AGR2 expression in prostate cancer tissue}

We further considered AGR2 protein expression in a patient cohort using a prostate TMA. The TMA consisted of specimens from 226 cases, of which 187 were informative. Cases were uninformative if their tissue spots contained no relevant epithelial cells (i.e., tumor or benign), if spots were physically missing, or if, for

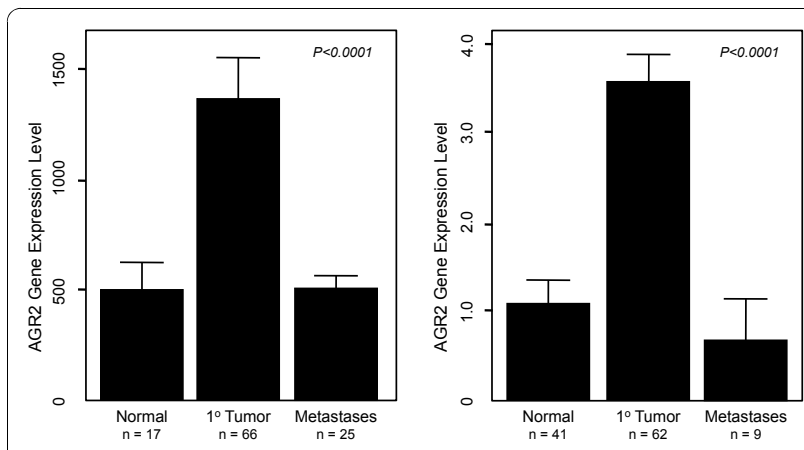

Figure 1 AGR2 transcript expression in prostate cancer. Two publically available datasets were used to examine AGR2 gene expression in human prostate samples [31,32]. (A) Dataset was from Yu, et al., and was generated using Affymetrix U95B Array [31]. (B) Dataset was from Lapointe, et al., and was generated using a CDNA microarray from the Stanford Microarray Database [32]. For each dataset, normalized data was available from the GEO database. The bars are the relative mean expression value \pm standard error of the mean. $P<0.0001$ for each multi group comparison (Kruskal-Wallis).
Table 1 Clinicopathologic parameters and AGR2 expression in patients with prostate cancer

\begin{tabular}{|c|c|c|c|}
\hline & $\begin{array}{c}\text { All } \\
\text { patients }\end{array}$ & $\begin{array}{c}\text { Mean AGR2 expression } \\
\text { (SE) }\end{array}$ & $\begin{array}{c}\mathrm{P}- \\
\text { value }\end{array}$ \\
\hline Total cases & 187 & $0.548(0.040)$ & \\
\hline Age at surgery & & & $0.929^{2}$ \\
\hline $\begin{array}{l}\text { Median } \\
\text { (range) }\end{array}$ & $65(46-76)$ & & \\
\hline Mean & 63.7 & & \\
\hline Gleason score & & & $0.986^{1}$ \\
\hline $2-6$ & 107 & $0.544(0.052)$ & \\
\hline $7-10$ & 80 & $0.553(0.064)$ & \\
\hline \multicolumn{4}{|l|}{ Stage } \\
\hline$|/| \mid$ & 122 & $0.559(0.054)$ & $0.764^{1}$ \\
\hline III/IV & 65 & $0.527(0.057)$ & \\
\hline pT stage & & & $0.767^{1}$ \\
\hline pT2-pT3a & 152 & $0.560(0.047)$ & \\
\hline pT3b & 35 & $0.495(0.076)$ & \\
\hline $\begin{array}{l}\text { Lymph node } \\
\text { status }\end{array}$ & & & $0.180^{1}$ \\
\hline Positive & 11 & $0.353(0.118)$ & \\
\hline Negative & 174 & $0.564(0.043)$ & \\
\hline Tumor margins & & & $0.347^{1}$ \\
\hline Positive & 64 & $0.490(0.060)$ & \\
\hline Negative & 123 & $0.578(0.053)$ & \\
\hline Capsular invasion & & & $0.484^{1}$ \\
\hline No invasion & 43 & $0.573(0.107)$ & \\
\hline Invasion & 144 & $0.540(0.042)$ & \\
\hline Organ confined & & & $0.477^{1}$ \\
\hline Yes & 93 & $0.598(0.066)$ & \\
\hline No & 94 & $0.498(0.047)$ & \\
\hline PSA ng/mL & & & $0.339^{2}$ \\
\hline $\begin{array}{l}\text { Median } \\
\text { (range) }\end{array}$ & $\begin{array}{l}9.6(0.6- \\
96.5)\end{array}$ & & $0.413^{1}$ \\
\hline Mean & 14.0 & & \\
\hline$<10$ & 88 & $0.509(0.057)$ & \\
\hline$\geq 10$ & 79 & $0.563(0.064)$ & \\
\hline
\end{tabular}

${ }^{1}$ Mann-Whitney, ${ }^{2}$ Spearman Correlation. Cases that were uninformative for a given variable were removed from the statistical analysis.

outcomes data, there was no information on disease recurrence. The characteristics of the patients on the TMA are listed in Table 1. AGR2, if present, was predominantly expressed in the cytoplasm of epithelial cells (Figure 2). When we examined AGR2 expression for each array spot, the level of AGR2 expression was increased in PIN lesions as well as adenocarcinoma compared to $\mathrm{BPH}$ and morphologically normal adjacent tissue (P 3). This was consistent with the cancer-specific expression of AGR2 shown in Figure 1. Representative images of weak, moderate, or strong AGR2 expression are shown in Figure 2. Overall, regional metastases tended to show AGR2 expression higher than $\mathrm{BPH}$ and normal tissue $(\mathrm{P}=0.027$ and $\mathrm{P}=0.030$, respectively; Figure 3). Moreover, there was an increase in AGR2 


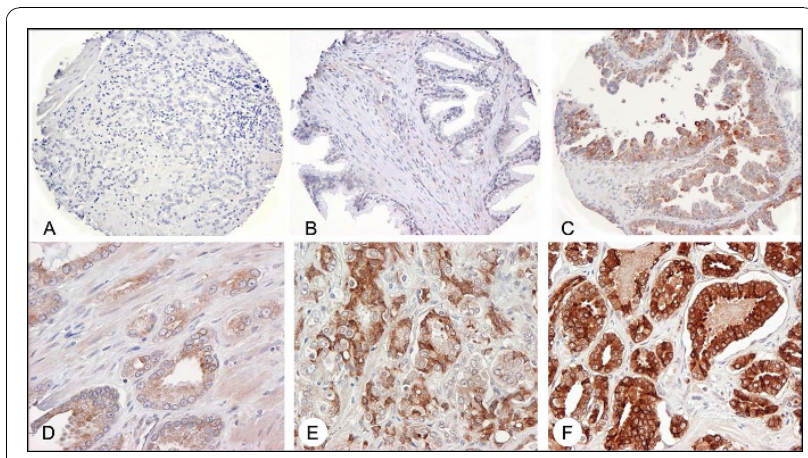

Figure 2 AGR2 immunohistochemistry. AGR2 staining was localized to the cytoplasm and membrane of cancer epithelial cells. (A) Tissue samples incubated with concentration-matched nonimmune rabbit lgG showed no staining. Shown are representative sections of (B) morphologically normal tissue, (C) PIN, and (D) a representative adenocarcinoma (Gleason grade 7) showing low staining intensity, (E) a representative adenocarcinoma (Gleason grade 8) showing moderate staining intensity, and (F) a representative adenocarcinoma (Gleason grade 6) showing high staining intensity.

expression in Gleason grades 3 and 4 compared to 2 ( $\mathrm{P}$ $<0.0001$ and $\mathrm{P}=0.0007$; Figure 4). There was a significant drop in expression in grade 5 tumors compared to grades 3 and $4(\mathrm{P}=0.0028$ and $\mathrm{P}=0.0085$; Figure 4$)$.

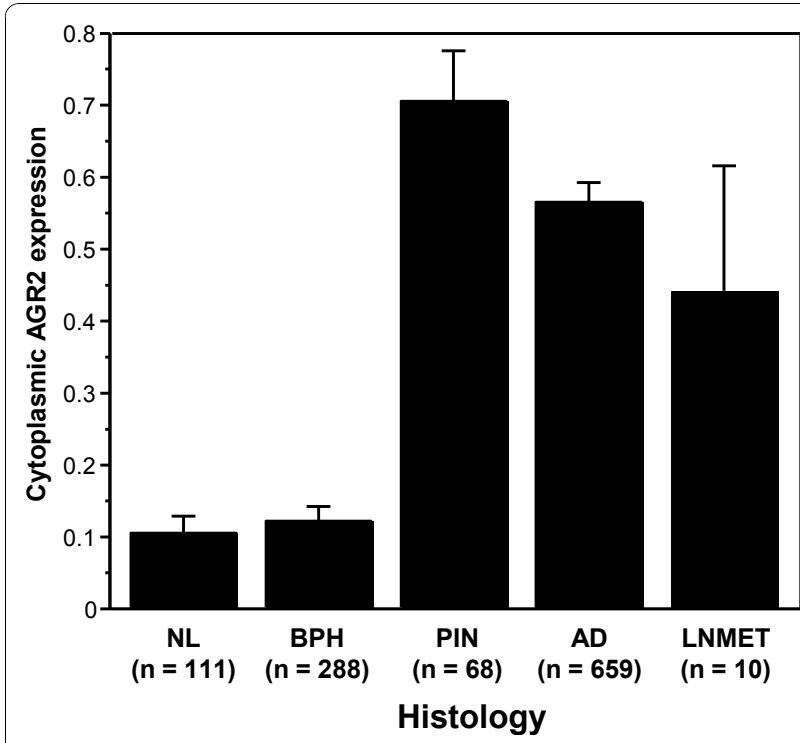

Figure 3 AGR2 expression by spot level histopathology. The barplots show the mean integrated AGR2 expression by TMA spotlevel histology in morphologically normal (NL), BPH, PIN, adenocarcinoma (AD), and lymph node metastases (LNMET); bars are standard errors. Levels of AGR2 expression were increased in PIN lesions and adenocarcinoma compared to BPH and morphologically normal adjacent tissue $(P<0.0001)$. Regional metastases showed increased $A G R 2$ expression compared to $\mathrm{BPH}$ and normal tissue ( $\mathrm{P}$ $=0.027$ and $P=0.030$, respectively).

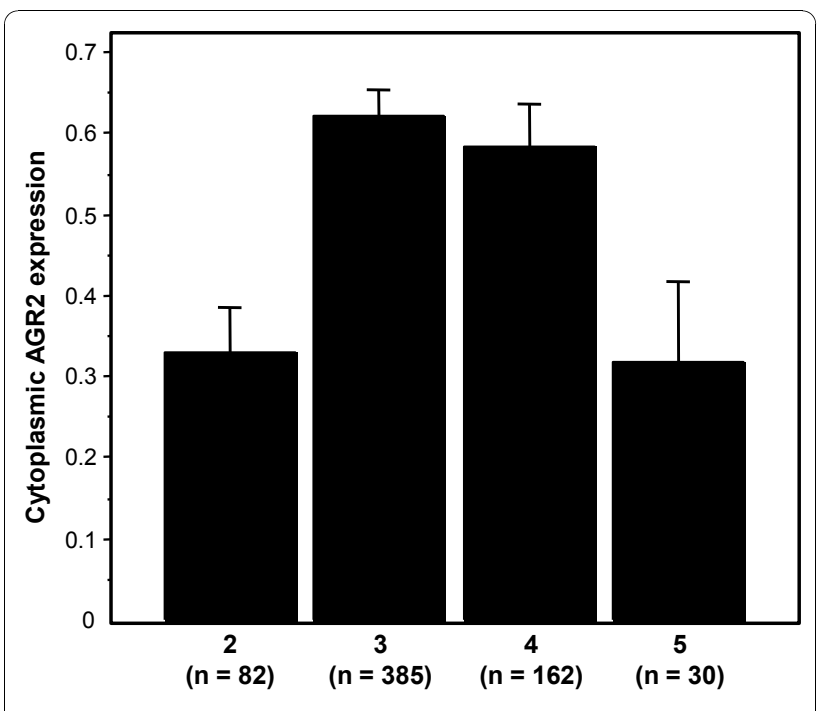

Spot Level Gleason Grade

Figure 4 AGR2 expression by spot level Gleason grade. The barplots show the mean integrated AGR2 expression by TMA spotlevel Gleason grade; bars are standard errors. Average AGR2 expression was increased in grades 3 and 4 compared to grade 2 ( $P$ $<0.0001$ and $P=0.0007)$ and grade $5(P=0.0028$ and $P=0.0085)$.

Decreased AGR2 expression in high-stage prostate cancer predicts greater probability of recurrence

The differential AGR2 expression in prostate cancer prompted us to examine possible links between expression and clinical outcomes. The outcomes measure we considered was tumor recurrence following radical prostatectomy as diagnosed by measurable blood PSA. AGR2 expression was not predictive of tumor recurrence either as a continuous or dichotomized variable $(\mathrm{P}=0.596$ and $\mathrm{P}=0.281$, Table 2$)$. Patients were also grouped into high stage (III and IV) versus low stage (I and II) subpopulations. AGR2 provided no predictive value for recurrence for individuals with low stage cancer. In contrast, AGR2 was a strong predictor of tumor recurrence for individuals with high stage prostate cancer (Figure 5). Specifically, relatively lower levels of AGR2 predicted a significantly greater chance of prostate cancer recurrence compared to higher levels $(\mathrm{P}=$ 0.009). The median recurrence-free time in the lower AGR2 group was 14 months compared to 38.5 months in the group with relatively higher AGR2 expression.

Although AGR2 expression was associated with longer time to recurrence in higher stage cancers, AGR2 did not significantly associate with any other clinicopathological variables in this subgroup, such as Gleason score, lymph node status, tumor margins, or PSA levels (Table 3). To see whether AGR2 was an independent predictor of survival, we used a multivariate Cox model including dichotomized AGR2 expression, Gleason sum, PSA levels, and 
Table 2 Univariate Cox model

\begin{tabular}{|c|c|c|c|c|c|c|}
\hline \multirow[b]{2}{*}{ Variable } & \multicolumn{3}{|c|}{ All Patients $(n=187)$} & \multicolumn{3}{|c|}{ Stage III/IV Patients $(n=65)$} \\
\hline & HR & $95 \% \mathrm{Cl}$ & P-Value & HR & $95 \% \mathrm{Cl}$ & P-Value \\
\hline AGR2 continuous & 0.89 & $0.57-1.38$ & 0.596 & 0.50 & $0.24-1.04$ & 0.062 \\
\hline AGR2 dichotomized & 0.75 & $0.44-1.27$ & 0.281 & 0.37 & $0.17-0.81$ & 0.013 \\
\hline Gleason sum ${ }^{1}$ & 3.78 & $2.26-6.33$ & $<0.0001$ & 1.88 & $0.90-3.93$ & 0.093 \\
\hline Preoperative PSA & 1.02 & $1.00-1.03$ & 0.011 & 1.00 & $0.98-1.02$ & 0.884 \\
\hline pT stage ${ }^{2}$ & 3.89 & $2.36-6.40$ & $<0.0001$ & 2.63 & $1.26-5.49$ & 0.010 \\
\hline
\end{tabular}

${ }^{1}$ Gleason sum was dichotomized as low $(<7)$ vs. high (7-10).

${ }^{2}$ pT stage was dichotomized as pT2-pT3a vs. pT3b.

pT stage (Table 4). For high stage patients, AGR2 expression showed a trend toward significance $(\mathrm{P}=0.087)$.

\section{Discussion}

AGR2 has been implicated in cancer pathogenesis and has been found to be up-regulated in multiple human cancers, including breast, lung, and prostate $[13,14,18-20,30]$. Our study has shown that AGR2 is higher in prostate cancer cells compared to non-malignant prostatic epithelial cells at the transcript and protein levels. This is consistent with other recent studies which have found an increase in AGR2 mRNA using microarray analysis of laser-capture microdissected cells and an increase in AGR2 protein levels [17-21,39,40]. Using TMA technology, we also verify a greatly enhanced AGR2 protein expression in malignant and early malignant PIN lesions compared to non-malignant epithelium. We observed that AGR2 levels were lower in advanced disease states as Gleason grade 5 spots

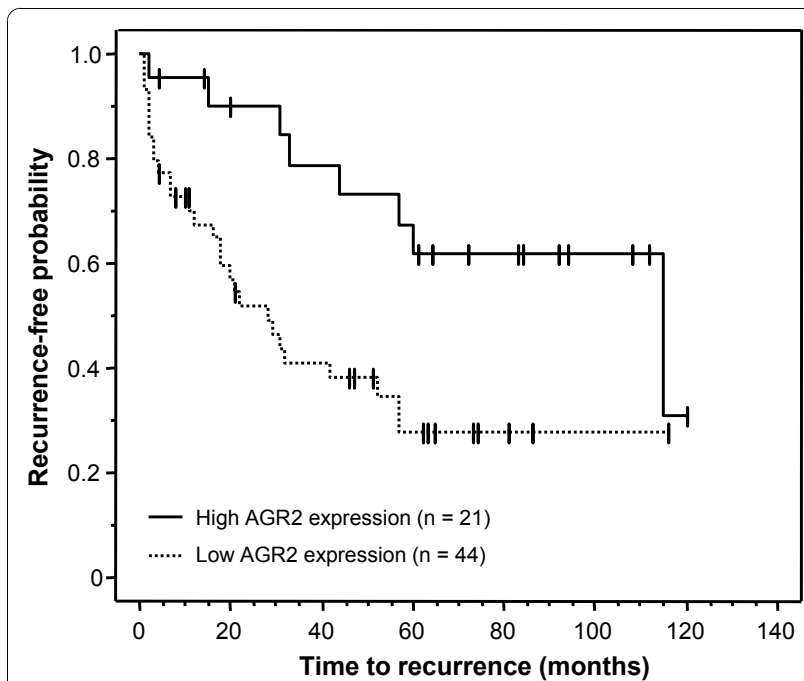

Figure 5 AGR2 levels predict prostate cancer recurrence in high stage patients. Solid line is relatively higher AGR2 levels (staining measure $\geq 0.79$ ); dashed line is relatively lower AGR2 levels $(<0.79)$. In men with stage III or IV prostate cancer, relatively lower levels of AGR2 predict a significantly greater chance of prostate cancer recurrence compared to those with higher levels $(P=0.009)$. expressed dramatically less AGR2 than grade 4 and grade 3 spots. Finally, we showed, for the first time, a novel predictive value for AGR2 expression with regard to tumor recurrence in individuals with higher stage disease. In this situation, relatively lower levels of AGR2 expression predicted a higher likelihood of tumor recurrence.

The exact biological role of AGR2 in humans is largely unknown. The AGR2 homolog in X. laevis, XAG2, has $73 \%$ similarity and $47 \%$ identity at the protein level [6] and plays a role in the differentiation of the mucussecreting cement gland found on the anterior aspect of the frog embryo [41]. The newt homolog, nAG, has been shown to induce cellular proliferation in denervated limbs [42]. In the adult, AGR2 expression is restricted to a limited number of tissues and cell types in the body suggesting it is not a ubiquitously expressed product [43]. In the intestine, for example, AGR2 is found in the goblet cells and appears necessary for the production of intestinal mucus $[44,45]$. In malignant cells from organs such as the breast and prostate, AGR2 may be involved in additional functions. Interestingly, in various models of tumor progression, increased AGR2 promotes cell migration, invasion, and presumably metastatic spread $[15,18,21,27,28,46,47]$. However, the story may be more complicated as recently $\mathrm{Bu}$, et al. observed that while over-expressed AGR2 in prostate cancer cells increased migration and invasion, it additionally repressed growth and proliferation [21]. The exact mechanistic role for AGR2 in these functions remains to be elucidated.

In our data, the lower expression of AGR2 in higher Gleason tumors appears to correlate with AGR2 being predictive of prostate cancer recurrence in individuals with higher stage cancers. Many studies report that AGR2 expression corresponds to a more differentiated phenotype $[13,30,46]$. Lower Gleason scores are indicative of well-differentiated tumors. If AGR2 indeed has opposing functions of promoting migration and invasion with higher expression yet allowing/promoting cellular proliferation upon decreased expression [21], it is intriguing to consider that our results reflect this balance of 
Table 3 Clinicopathologic parameters and AGR2 expression in patients with high stage prostate cancer

\begin{tabular}{|c|c|c|c|c|c|c|}
\hline & Stage III/IV patients & $\begin{array}{c}\text { Mean AGR2 } \\
\text { expression (SE) }\end{array}$ & P-value & Low AGR2 & High AGR2 & P-value \\
\hline Total cases & 65 & $0.53(0.057)$ & & 44 & 21 & \\
\hline Age at surgery & & & $0.762^{2}$ & & & $0.763^{1}$ \\
\hline Median (range) & $66(50-76)$ & & & $66(50-76)$ & $65(50-73)$ & \\
\hline Mean & 64.6 & & & 64.8 & 64.3 & \\
\hline Gleason score & & & $0.098^{1}$ & & & $0.161^{3}$ \\
\hline $2-6$ & 22 & $0.664(0.104)$ & & 12 & 10 & \\
\hline $7-10$ & 43 & $0.457(0.066)$ & & 32 & 11 & \\
\hline pT stage & & & $0.451^{1}$ & & & $0.111^{3}$ \\
\hline рT2-рT3a & 30 & $0.565(0.087)$ & & 17 & 13 & \\
\hline pT3b & 35 & $0.495(0.076)$ & & 27 & 8 & \\
\hline Lymph node status & & & $0.118^{1}$ & & & $0.480^{3}$ \\
\hline Positive & 11 & $0.353(0.118)$ & & 9 & 2 & \\
\hline Negative & 54 & $0.563(0.064)$ & & 35 & 19 & \\
\hline Tumor margins & & & $0.990^{1}$ & & & $0.794^{3}$ \\
\hline Positive & 35 & $0.536(0.087)$ & & 23 & 12 & \\
\hline Negative & 30 & $0.517(0.072)$ & & 21 & 9 & \\
\hline Capsular invasion & & & $0.805^{1}$ & & & $>0.999^{3}$ \\
\hline No invasion & 4 & $0.507(0.174)$ & & 3 & 1 & \\
\hline Invasion & 61 & $0.529(0.060)$ & & 41 & 20 & \\
\hline PSA ng/mL & & & $0.414^{2}$ & & & $0.089^{1}$ \\
\hline Median (range) & $11.9(2.1-96.5)$ & & $0.353^{1}$ & & & $0.092^{3}$ \\
\hline Mean & 18.7 & & & & & \\
\hline$<10$ & 25 & $0.607(0.103)$ & & 14 & 11 & \\
\hline$\geq 10$ & 32 & $0.463(0.073)$ & & 25 & 7 & \\
\hline
\end{tabular}

${ }^{1}$ Mann-Whitney, ${ }^{2}$ Spearman Correlation, ${ }^{3}$ Fisher's Exact Test. Cases that were uninformative for a given variable were removed from the statistical analysis.

functional activity. We therefore hypothesize that in later stage prostate cancer, the balance towards increased proliferation (e.g., lower AGR2 expression) outweighs the need for enhanced migration and invasion (e.g., higher AGR2 expression). We are currently testing this hypothesis both in vitro and in vivo. Of interest Zhang et al., also used TMA technology to examine the associate of AGR2 expression levels with prostate cancer outcome [19]. Similar to us, they observed an increase in AGR2 expression in prostate cancer compared to normal or benign tissue. However, in apparent contrast to our results, they observed that increased AGR2 was associated with a poorer outcome [19]. While the explanation for this apparent discrepancy is unclear, it should be noted that Zhang et al. considered overall survival while our outcome measure was disease-specific recurrence. We did not have sufficient numbers of patients in our cohort who died from the disease in order to conduct meaningful statistical analysis of survival. Whether or not other subtle differences in treatment, clinical history, and/or demographics existed in the patient cohort at UCLA versus the Royal Liverpool University Hospital is difficult to assess. Nevertheless, whether the prognostic significance of AGR2 varies based on the outcome

Table 4 Multivariate Cox model

\begin{tabular}{|c|c|c|c|c|c|c|}
\hline \multirow[b]{2}{*}{ Variable } & \multicolumn{3}{|c|}{ All Patients $(n=165)^{2}$} & \multicolumn{3}{|c|}{ Stage III/IV Patients $(n=57)^{3}$} \\
\hline & HR & $95 \% \mathrm{Cl}$ & P-Value & HR & $95 \% \mathrm{Cl}$ & P-Value \\
\hline AGR2 dichotomized & 0.83 & $0.46-1.52$ & 0.549 & 0.44 & $0.17-1.13$ & 0.087 \\
\hline Gleason sum ${ }^{1}$ & 3.18 & $1.67-6.08$ & 0.0005 & 1.14 & $0.42-3.07$ & 0.795 \\
\hline Preoperative PSA & 1.00 & $0.98-1.01$ & 0.713 & 0.99 & $0.97-1.01$ & 0.440 \\
\hline pT stage ${ }^{2}$ & 2.39 & $1.28-4.47$ & 0.0064 & 2.57 & $1.00-6.65$ & 0.051 \\
\hline
\end{tabular}

${ }^{1}$ Gleason sum was dichotomized as low $(<7)$ vs. high (7-10).

2 pT stage was dichotomized as pT2-pT3a vs. pT3b.

${ }^{3}$ In all patients, 165 of 187 cases were informative for all four variables.

${ }^{4}$ In stage III/IV patients, 57 of 65 cases were informative for all four variables. 
measurement (i.e., disease recurrence versus survival) warrants further investigation.

Our group, as well as others, is also examining AGR2 as a potential prostate cancer biomarker. In this regard, AGR2 has the following interesting attributes. First, it appears to be expressed at relatively high levels in individuals with prostate cancer; expression is lower from normal or non-malignant prostatic epithelium. Second, since AGR2 is secreted, there is the likelihood that the protein can be detected in blood or urine. Indeed $\mathrm{Bu}$ et al., have detected increased AGR2 transcript in urine sediments from prostate cancer patients [21]. That AGR2 is secreted is supported by our results as well as by mass spectrometry proteomic analysis of 2-D gel electrophoresis spots reported in the literature [48]. We are currently exploring whether AGR2 detected in body fluids is an accurate gauge for prostate cancer initiation, progression, and/or outcome. In particular, we are developing an assay to detect subnanogram per ml levels of AGR2. New monoclonal AGR2 antibodies need to be produced, however, since we found that the commercially available one did not recognize native AGR2 in solution.

\section{Conclusions}

In summary, we found that AGR2 is a secreted protein expressed at relatively high levels by prostate cancer cells and cells in PIN lesions. We found that a relatively higher expression of AGR2 in patients with high stage prostate cancer stratified these individuals as less likely to have a tumor recurrence.

\section{Acknowledgements \\ We thank Rebecca Schatz and Adam Goodglick for helpful discussion. This work was supported in part by the Early Detection Research Network NCI CA86366 (LG and DC) and NCI CA111244 (AYL).}

\section{Author details}

'Department of Pathology and Laboratory Medicine, David Geffen School of Medicine, University of California, Los Angeles, 10833 Le Conte Ave., Los Angeles, CA 90095, USA. ${ }^{2}$ Department of Biostatistics, David Geffen School of Medicine, University of California, Los Angeles, 10833 Le Conte Ave., Los Angeles, CA 90095, USA. ${ }^{3}$ Department of Human Genetics, David Geffen School of Medicine, University of California, Los Angeles, 10833 Le Conte Ave., Los Angeles, CA 90095, USA. ${ }^{4}$ Department of Urology, University of Washington, 1959 NE Pacific St., Seattle, WA 98195, USA. ${ }^{5}$ Institute for Stem Cell and Regenerative Medicine, University of Washington, 1959 NE Pacific St., Seattle, WA 98195, USA. ${ }^{6}$ Institute for Systems Biology, University of Washington, 1959 NE Pacific St., Seattle, WA 98195, USA. 'Jonsson Comprehensive Cancer Center, David Geffen School of Medicine, University of California, Los Angeles, 10833 Le Conte Ave., Los Angeles, CA 90095, USA.

\section{Authors' contributions}

ELM performed tissue immunoassays, statistical analysis and data interpretation, and manuscript preparation. VM provided statistical analysis and data interpretation. MA scored the TMA. LB performed the mRNA microarray analyses. SH provided oversight of statistical analyses. ESL performed Western blot analyses. LAK \& YZ conducted software analysis, Western blot analyses, and ELISA. DC aided in study design. AYL \& LG aided in study design, data interpretation, and manuscript preparation. All authors read and approved the final manuscript.

\section{Competing interests}

The authors declare that they have no competing interests.

Received: 14 May 2010 Accepted: 13 December 2010

Published: 13 December 2010

\section{References}

1. Jemal A, Siegel R, Xu J, Ward E: Cancer statistics, 2010. CA: a cancer journal for clinicians 2010, 60(5):277-300.

2. Pascal LE, Deutsch EW, Campbell DS, Korb M, True LD, Liu AY: The urologic epithelial stem cell database (UESC) - a web tool for cell type-specific gene expression and immunohistochemistry images of the prostate and bladder. BMC urology 2007, 7:19.

3. Nielsen $H$, Engelbrecht J, Brunak S, von Heijne G: A neural network method for identification of prokaryotic and eukaryotic signal peptides and prediction of their cleavage sites. Int J Neural Syst 1997, 8(56):581-599.

4. Krogh A, Larsson B, von Heijne G, Sonnhammer EL: Predicting transmembrane protein topology with a hidden Markov model: application to complete genomes. J Mol Biol 2001, 305(3):567-580.

5. Pascal LE, Vencio RZ, Page LS, Liebeskind ES, Shadle CP, Troisch $P$, Marzolf $B$, True LD, Hood LE, Liu AY: Gene expression relationship between prostate cancer cells of Gleason 3,4 and normal epithelial cells as revealed by cell type-specific transcriptomes. BMC Cancer 2009, 9:452.

6. Thompson DA, Weigel RJ: hAG-2, the human homologue of the Xenopus laevis cement gland gene XAG-2, is coexpressed with estrogen receptor in breast cancer cell lines. Biochemical and biophysical research communications 1998, 251(1):111-116.

7. Persson S, Rosenquist M, Knoblach B, Khosravi-Far R, Sommarin M, Michalak M: Diversity of the protein disulfide isomerase family: identification of breast tumor induced Hag2 and Hag3 as novel members of the protein family. Molecular phylogenetics and evolution 2005, 36(3):734-740.

8. Zweitzig DR, Smirnov DA, Connelly MC, Terstappen LW, O'Hara SM, Moran E: Physiological stress induces the metastasis marker AGR2 in breast cancer cells. Molecular and cellular biochemistry 2007, 306(12):255-260.

9. Pohler E, Craig AL, Cotton J, Lawrie L, Dillon JF, Ross P, Kernohan N, Hupp TR: The Barrett's antigen anterior gradient- 2 silences the $\mathrm{p} 53$ transcriptional response to DNA damage. Mol Cell Proteomics 2004, 3(6):534-547.

10. Ferraro A, Altieri F, Coppari S, Eufemi M, Chichiarelli S, Turano C: Binding of the protein disulfide isomerase isoform ERp60 to the nuclear matrixassociated regions of DNA. Journal of cellular biochemistry 1999, 72(4):528-539.

11. Turano C, Coppari S, Altieri F, Ferraro A: Proteins of the PDI family: unpredicted non-ER locations and functions. Journal of cellular physiology 2002, 193(2):154-163.

12. Mandel R, Ryser HJ, Ghani F, Wu M, Peak D: Inhibition of a reductive function of the plasma membrane by bacitracin and antibodies against protein disulfide-isomerase. Proceedings of the National Academy of Sciences of the United States of America 1993, 90(9):4112-4116.

13. Fritzsche FR, Dahl E, Pahl S, Burkhardt M, Luo J, Mayordomo E, Gansukh T, Dankof A, Knuechel R, Denkert C, et al: Prognostic relevance of AGR2 expression in breast cancer. Clin Cancer Res 2006, 12(6):1728-1734.

14. Innes HE, Liu D, Barraclough R, Davies MP, O'Neill PA, Platt-Higgins A, de Silva Rudland S, Sibson DR, Rudland PS: Significance of the metastasisinducing protein AGR2 for outcome in hormonally treated breast cancer patients. British journal of cancer 2006, 94(7):1057-1065.

15. Liu D, Rudland PS, Sibson DR, Platt-Higgins A, Barraclough R: Human homologue of cement gland protein, a novel metastasis inducer associated with breast carcinomas. Cancer research 2005, 65(9):3796-3805.

16. Shen D, Chang HR, Chen Z, He J, Lonsberry V, Elshimali Y, Chia D, Seligson D, Goodglick L, Nelson SF, et al: Loss of annexin A1 expression in human breast cancer detected by multiple high-throughput analyses. Biochemical and biophysical research communications 2005, 326(1):218-227. 
17. Zhang JS, Gong A, Cheville JC, Smith DI, Young CY: AGR2, an androgeninducible secretory protein overexpressed in prostate cancer. Genes, chromosomes \& cancer 2005, 43(3):249-259.

18. Zhang Y, Ali TZ, Zhou H, D'Souza DR, Lu Y, Jaffe J, Liu Z, Passaniti A, Hamburger AW: ErbB3 binding protein 1 represses metastasis-promoting gene anterior gradient protein 2 in prostate cancer. Cancer research 2010, 70(1):240-248.

19. Zhang Y, Forootan SS, Liu D, Barraclough R, Foster CS, Rudland PS, Ke Y: Increased expression of anterior gradient-2 is significantly associated with poor survival of prostate cancer patients. Prostate cancer and prostatic diseases 2007, 10(3):293-300.

20. Liu AY, Zhang H, Sorensen CM, Diamond DL: Analysis of prostate cancer by proteomics using tissue specimens. The Journal of urology 2005, 173(1):73-78.

21. Bu H, Bormann $S$, Schafer $G$, Horninger W, Massoner P, Neeb A, Lakshmanan VK, Maddalo D, Nestl A, Sultmann $H$, et al: The anterior gradient 2 (AGR2) gene is overexpressed in prostate cancer and may be useful as a urine sediment marker for prostate cancer detection. Prostate 2010.

22. Vivekanandan P, Micchelli ST, Torbenson M: Anterior gradient-2 is overexpressed by fibrolamellar carcinomas. Hum Pathol 2009, 40(3):293-299

23. Riener MO, Pilarsky C, Gerhardt J, Grutzmann R, Fritzsche FR, Bahra M, Weichert W, Kristiansen G: Prognostic significance of AGR2 in pancreatic ductal adenocarcinoma. Histology and histopathology 2009, 24(9):1121-1128

24. Lowe AW, Olsen M, Hao Y, Lee SP, Taek Lee K, Chen X, van de Rijn M, Brown PO: Gene expression patterns in pancreatic tumors, cells and tissues. PloS One 2007, 2(3):e323.

25. lacobuzio-Donahue CA, Maitra A, Olsen M, Lowe AW, van Heek NT, Rosty C, Walter K, Sato N, Parker A, Ashfaq R, et al: Exploration of global gene expression patterns in pancreatic adenocarcinoma using CDNA microarrays. Am J Pathol 2003, 162(4):1151-1162.

26. Lee S, Bang S, Song K, Lee I: Differential expression in normal-adenomacarcinoma sequence suggests complex molecular carcinogenesis in colon. Oncol Rep 2006, 16(4):747-754.

27. Wang $Z$, Hao Y, Lowe AW: The adenocarcinoma-associated antigen, AGR2, promotes tumor growth, cell migration, and cellular transformation. Cancer research 2008, 68(2):492-497.

28. Wu ZS, Wu Q, Ding $X D$, Wang $H Q$, Shen $Y X$, Fang SY: [Expression of a novel metastasis-inducing protein human anterior gradient-2 (AGR2) in breast cancer and its clinical and prognostic significance]. Zhonghua bing li xue za zhi Chinese journal of pathology 2008, 37(2):109-113.

29. Barraclough DL, Platt-Higgins A, de Silva Rudland S, Barraclough R, Winstanley J, West CR, Rudland PS: The metastasis-associated anterior gradient 2 protein is correlated with poor survival of breast cancer patients. Am J Pathol 2009, 175(5):1848-1857.

30. Fritzsche FR, Dahl E, Dankof A, Burkhardt M, Pahl S, Petersen I, Dietel M, Kristiansen G: Expression of AGR2 in non small cell lung cancer. Histology and histopathology 2007, 22(7):703-708.

31. Yu YP, Landsittel D, Jing L, Nelson J, Ren B, Liu L, McDonald C, Thomas R, Dhir R, Finkelstein $S$, et al: Gene expression alterations in prostate cancer predicting tumor aggression and preceding development of malignancy. J Clin Oncol 2004, 22(14):2790-2799.

32. Lapointe J, Li C, Higgins JP, van de Rijn M, Bair E, Montgomery K, Ferrari M, Egevad L, Rayford W, Bergerheim U, et al: Gene expression profiling identifies clinically relevant subtypes of prostate cancer. Proceedings of the National Academy of Sciences of the United States of America 2004, 101(3):811-816.

33. Seligson D, Horvath $S$, Huerta-Yepez S, Hanna S, Garban H, Roberts A, Shi T, Liu X, Chia D, Goodglick L, et al: Expression of transcription factor Yin Yang 1 in prostate cancer. International journal of oncology 2005, 27(1):131-141.

34. Seligson DB, Hongo F, Huerta-Yepez S, Mizutani Y, Miki T, Yu H, Horvath S, Chia D, Goodglick L, Bonavida B: Expression of X-linked inhibitor of apoptosis protein is a strong predictor of human prostate cancer recurrence. Clin Cancer Res 2007, 13(20):6056-6063.

35. Seligson DB, Horvath S, Shi T, Yu H, Tze S, Grunstein M, Kurdistani SK: Global histone modification patterns predict risk of prostate cancer recurrence. Nature 2005, 435(7046):1262-1266.
36. Yoon NK, Seligson DB, Chia D, Elshimali Y, Sulur G, Li A, Horvath S, Maresh E, Mah V, Bose S, et al: Higher expression levels of 14-3-3sigma in ductal carcinoma in situ of the breast predict poorer outcome. Cancer Biomark 2009, 5(4):215-224.

37. Mah V, Seligson DB, Li A, Marquez DC, Wistuba II, Elshimali Y, Fishbein MC, Chia D, Pietras RJ, Goodglick L: Aromatase expression predicts survival in women with early-stage non small cell lung cancer. Cancer research 2007, 67(21):10484-10490.

38. Yoon NK, Maresh EL, Elshimali Y, Li A, Horvath S, Seligson DB, Chia D, Goodglick L: Elevated MED28 expression predicts poor outcome in women with breast cancer. BMC Cancer 2010, 10:335.

39. Tomlins SA, Mehra R, Rhodes DR, Cao X, Wang L, Dhanasekaran SM, Kalyana-Sundaram S, Wei JT, Rubin MA, Pienta KJ, et al: Integrative molecular concept modeling of prostate cancer progression. Nat Genet 2007, 39(1):41-51.

40. True L, Coleman I, Hawley S, Huang CY, Gifford D, Coleman R, Beer TM, Gelmann E, Datta M, Mostaghel E, et al: A molecular correlate to the Gleason grading system for prostate adenocarcinoma. Proceedings of the National Academy of Sciences of the United States of America 2006, 103(29):10991-10996.

41. Aberger F, Weidinger G, Grunz H, Richter K: Anterior specification of embryonic ectoderm: the role of the Xenopus cement gland-specific gene XAG-2. Mechanisms of development 1998, 72(1-2):115-130.

42. Kumar A, Godwin JW, Gates PB, Garza-Garcia AA, Brockes JP: Molecular basis for the nerve dependence of limb regeneration in an adult vertebrate. Science (New York, NY) 2007, 318(5851):772-777.

43. Uhlen M, Bjorling E, Agaton C, Szigyarto CA, Amini B, Andersen E, Andersson AC, Angelidou P, Asplund A, Asplund C, et al: A human protein atlas for normal and cancer tissues based on antibody proteomics. $\mathrm{Mol}$ Cell Proteomics 2005, 4(12):1920-1932.

44. Park SW, Zhen G, Verhaeghe C, Nakagami Y, Nguyenvu LT, Barczak AJ, Killeen N, Erle DJ: The protein disulfide isomerase AGR2 is essential for production of intestinal mucus. Proceedings of the National Academy of Sciences of the United States of America 2009, 106(17):6950-6955.

45. Komiya T, Tanigawa Y, Hirohashi S: Cloning of the gene gob-4, which is expressed in intestinal goblet cells in mice. Biochimica et biophysica acta 1999, 1444(3):434-438.

46. Fletcher GC, Patel S, Tyson K, Adam PJ, Schenker M, Loader JA, Daviet L, Legrain P, Parekh R, Harris AL, et al: hAG-2 and hAG-3, human homologues of genes involved in differentiation, are associated with oestrogen receptor-positive breast tumours and interact with metastasis gene C4.4a and dystroglycan. British journal of cancer 2003, 88(4):579-585.

47. Smirnov DA, Zweitzig DR, Foulk BW, Miller MC, Doyle GV, Pienta KJ, Meropol NJ, Weiner LM, Cohen SJ, Moreno JG, et al: Global gene expression profiling of circulating tumor cells. Cancer research 2005, 65(12):4993-4997.

48. Kovalev LI, Shishkin SS, Khasigov PZ, Dzeranov NK, Kazachenko AV, Toropygin I, Mamykina SV: [Identification of AGR2 protein, a novel potential cancer marker, using proteomics technologies]. Prikl Biokhim Mikrobiol 2006, 42(4):480-484.

\section{Pre-publication history}

The pre-publication history for this paper can be accessed here: http://www.biomedcentral.com/1471-2407/10/680/prepub

\section{doi:10.1186/1471-2407-10-680}

Cite this article as: Maresh et al: Differential expression of anterio gradient gene AGR2 in prostate cancer. BMC Cancer 2010 10:680. 